ORIGINAL ARTICLE

\title{
Association of lipids with coronary heart disease in a saudi population
}

\author{
Associação de lípidos com doença cardíaca coronariana \\ em população saudita
}

Mohmed Elfatih Ashmaig ${ }^{1}$, Khalifa Ashmeik², Atif Ahmed², Samia Sobki ${ }^{3}$ Muheeb Abdulla²

\begin{abstract}
Background: The Saudi population is known to have an unhealthy diet in addition to physical inactivity.

Objective:To investigate the lipid-mediated risk factors that might be associated with increased incidence of coronary heart diseasein the Saudi population as this was found in Western populations.

Materials and Methods: Two hundred and twenty subjects suspected of having coronary heart disease underwent coronary angiography and blood draw following a 12-hour fast. Total and HDL cholesterol, triglycerides, Lp(a) and lipoprotein lipase were measured by standard methods. Small, dense LDL was measured by the iodixanol method with an ultracentrifugation of only 2.5 hours.

Results: One hundred and forty subjects were found to be positive for coronary heart disease while 80 subjects were shown to be negative for this disease. Statistically significant risk factors for coronary heart disease in the Saudi population were hypertriglyceridemia (1.93 \pm 0.95 versus $1.45 \pm 0.16$ mmol/L; $<$ <.0001); low HDL cholesterol (1.09 \pm 0.55 vs $1.33 \pm 0.63$ mmol/L, $p=0.0001)$; high Lp(a) (46.8 \pm 45.58 versus 29.06 $\pm 17.03 \mathrm{mg} / \mathrm{dL} ; \mathrm{p}=0.019)$; and the presence of small, dense LDL (1.0314 \pm 0.0028 versus $1.0300 \pm 0.0003 \mathrm{~g} / \mathrm{kg} ; \mathrm{p}=0.0099)$. Total cholesterol $(4.99 \pm 1.11$ versus $4.75 \pm 1.11 \mathrm{mmol} / \mathrm{L} ; \mathrm{p}=0.099)$, LPL (35.56 \pm 26.6 versus $27.89 \pm 11.96 \mathrm{IU} / \mathrm{L} ; \mathrm{p}<0.059)$, and LDL cholesterol $(3.06 \pm 1.12$ versus $2.79 \pm 1.08 \mathrm{mmol} / \mathrm{L} ; \mathrm{p}=0.08)$ were not found to be statistically significant coronary heart disease risk factors.

Conclusions: This study indicates that high TG, low HDL, high Lp(a) and the presence of small, dense LDL may contribute to the incidence of coronary heart disease and that TC was not significantly associated with incidence of coronary heart disease in the Saudi population.
\end{abstract}

Keywords: Coronary disease; triglycerides; cholesterol, HDL; LDL; lipoproteins.

\section{Resumo}

Contexto: A população saudita é conhecida por apresentar dietas não saudáveis, além de inatividade física.

Objetivo: Investigar os lipídeos como fatores de risco que podem associar-se com o aumento da incidência de doença cardíaca coronariana na população saudita, uma vez que isso foi encontrado na população ocidental.

Materiais e Métodos: Duzentos e vinte indivíduos com suspeita de doença cardíaca coronariana submeteram-se a angiografia coronária e coleta de sangue, após jejum de 12 horas. Colesterol total e HDL, triglicerídeos, Lp(a) e lipase lipoproteica foram calculados por métodos padrão. LDL pequena e densa foi medida pelo método do iodixanol com ultracentrifugação por apenas 2,5 horas.

Resultados: Cento e quarenta indivíduos apresentaram resultado positivo para doença cardíaca coronariana, enquanto 80 pacientes mostraram resultado negativo. Os fatores de risco estatisticamente significantes para doença cardíaca coronariana na população saudita foram hipertrigliceridemia

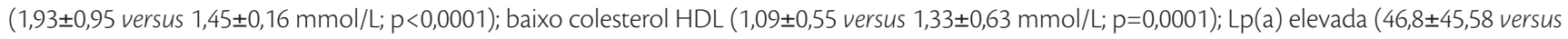
$29,06 \pm 17,03 \mathrm{mg} / \mathrm{dL} ; \mathrm{p}=0,019)$ e a presença de $\mathrm{LDL}$ pequena e densa $(1,0314 \pm 0,0028$ versus $1,0300 \pm 0,0003 \mathrm{~g} / \mathrm{kg} ; \mathrm{p}=0,0099)$. Colesterol total $(4,99 \pm 1,11$ versus 4,75 $\pm 1,11 \mathrm{mmol} / \mathrm{L} ; \mathrm{p}=0,099)$, colesterol $\mathrm{LPL}(35,56 \pm 26,6$ versus $27,89 \pm 11,96 \mathrm{IU} / \mathrm{L} ; \mathrm{p}<0,059)$ e $\mathrm{LDL}(3,06 \pm 1,12$ versus $2,79 \pm 1,08 \mathrm{mmol} / \mathrm{L} ; \mathrm{P}=0,08)$ não foram fatores de risco estatisticamente significantes para doença cardíaca coronariana.

Conclusões: Este estudo indica que elevados triglicerídeos, baixo HDL, elevada Lp(a) e a presença de LDL pequena e densa podem contribuir para a incidência de doença cardíaca coronariana. O colesterol total não foi significantemente associado à incidência de doença cardíaca coronariana na população saudita.

Palavras-chave: Doença das coronárias; triglicerídeos; colesterol HDL; lipoproteínas LDL; lipoproteínas.

1 Berkeley Heart Lab. Inc, California, USA.

2 Prince Sultan Cardiac Center, Riyadh Military Hospital, Saudi Arabia.

3 Department of Pathology, Clinical Chemistry Division, Riyadh Military Hospital, Riyadh, Saudi Arabia.

No conflicts of interest declared concerning the publication of this article.

Submetido em: 10.6.2010 Aceito em: 31.5.2011

J Vasc Bras. 2011;10(2):131-136. 


\section{Introduction}

Coronary heart disease (CHD) is the leading cause of morbidity and mortality inindustrial and developing countries. The Framingham Heart Study commenced in 1948 toidentify common risk factors contributing to CHD in over 5,000 men and women between the ages of 30 and $62^{1}$.As part of the Framingham Study, cholesterol was monitored in subjects whohad not yet developed symptoms of CHD. The data showed that in subjects less than 50 yearsold, CHD was related to their total cholesterol (TC) level, but no relationship was found insubjects over 50 years old $^{2}$. The Prospective Cardiovascular Münster(PROCAM), another epidemiological heartstudy that ran from 1979 to 1985 , analyzed data from more than 26,000 subjects and isconsidered the first study to demonstrate an epidemiological link between plasma TG levels andCHD ${ }^{3}$.

The Helsinki Heart Study, which focused on CHD prevention in a group of dyslipidemic middle-agedmen who were free from CHD or any other major illness,demonstrated anepidemiological link between plasma triglyceride level and $\mathrm{CHD}^{4,5}$. A meta-analysis of the PROCAM and Helsinki heart studies in which the patient'striglyceride levels were measured in a fasting state identified hypertriglyceridemia as a riskfactor for $\mathrm{CHD}^{6,7}$. In a 15 -year long populationbased prospective study of 11,068 Japanesesubjects aged between 40-69 years initially free of CHD or stroke, the incidence of CHDwas positively correlated to high triglycerides in both genders ${ }^{8}$.Furthermore, a 17-year meta-analysis of population-based prospective studies of $46,413 \mathrm{men}$ and 10,864 women confirmed that plasma triglyceride level is indeed a significant riskfactor for cardiovascular disease independent of HDL-cholesterol levels for both men andwomen'. Though cholesterol efflux is considered to be one of the most important parts of reverse cholesterol transport (RCT), removing cholesterol from the macrophages in the subintima to the liver for excretion, mediated by both active and passive processes ${ }^{10,11}$.

There is now a wealth of evidence from cross-sectional and prospective studies to indicate that LDL particle size is significantly associated with CHD and predictive of increased coronary risk. The relationship between small, dense LDL and CHD risk has been described in a range of different situations ${ }^{12-21}$. One underlying mechanism to explain the production of small, dense LDL, involves the overproduction and increased residence time of large, triacylglycerol-rich VLDL in the postprandial phase, a situation thought to involve the pathways of insulin resistance ${ }^{22,23}$. Hence, an increase in the number of small, dense LDL particles may originate from a defect in the metabolism of triglyceride-rich lipoproteins as described byBerneisandKrauss ${ }^{22}$. There are a number of possible mechanisms to explain the link between small, denseLDL and CHD. Firstly, the passage of serum lipoproteins into the arterial wall is known to be a function of particle size, so that small, dense LDL more readily penetratethe artery wall than larger $\mathrm{LDL}^{13}$. Arterial proteoglycans may selectively bind small, dense LDL with higher affinity, possibly through a specific apolipoprotein B (apoB) binding site ${ }^{23}$.

The hypothesis of this study is that the predominance of small dense LDL and the elevated levelsof traditional coronary risk factors influenced by diet and physical inactivity might play a role asmajor risk factors for CHD in an angiographically defined unique group in the Saudi Arabianpopulation. This under-studied Saudi population has been targeted for multiple lipid-mediatedrisk factors measurement, particularly the small, dense LDL. The objective of this study was to evaluate this hypothesis on the strength of the availableevidence that the Saudi population has a diet and lifestyle that is inappropriate for cardiovascularhealth ${ }^{24}$.We hypothesize that the Saudi population will demonstrate increased cardiovascular riskas determined by traditional and emerging biomarkers of CHD risk, particularly small, dense LDL.

\section{Materials and methods}

\section{Subjects}

The ethical approval from the local medical ethical committeeatPrinceSultanCardiac Centrein Riyadh, Saudi Arabia, was obtained before the study was started. Informedwritten consent was obtained from all subjects before blood draw. Two-hundred and twentysubjects were randomly selected and recruited from the Cardiology Department at Prince Sultan Cardiac Center ifthey were suspected of having CHD (not previously diagnosed as CHD patient) and were not on lipids lowering medicine or any prescribed medicine except insulin or oral diabetes control medicines. The subjects were selected for coronary angiographybased on one or more of the following criteria: chest pain, shortness of breath, resting orexercise stress ECG changes (such as abnormal Q-waves, ST depression or ST elevation), orhypertension. The subjects were then divided into two groups depending on the findings ofthe coronary angiogram:

1. positive for $\mathrm{CHD}(\mathrm{CHD}+)$, if an occlusion of $\geq 50 \%$ in any coronaryartery vessel was detected;all subjects had at least one or more vessel of 90 to 100 occlusion;

2. negative for CHD (CHD-), if no occlusion was detected bycoronary angiography. 
Subjects with long hospitalization, severe or chronic illness such as cancer or renal disease were excluded from the study.

\section{Heparin}

All subjects in this study received a heparin dose calculated according to their body mass index (data not shown) for the angiography procedure and release of capillary-boundlipoproteins lipase (LPL) before the sample was drawn.

\section{Blood collection}

All subjects fasted for 12 hours, and then venous blood was obtained by venesectionusing a 21-gauge Venflonneedle just before the angiogram procedure started. Blood was collected into plainSST tubes for lipids (TC, TG, HDL, LPL, $\mathrm{Lp}(\mathrm{a})$ and LDL). Small, dense LDLwas measured from serum samples stored at $-70^{\circ} \mathrm{C}$. All subjects then underwent a standardcoronary angiography carried out by a cardiologist at Prince Sultan Cardiac Center.

\section{Plasma lipid and lipoprotein analysis}

TC, TG and HDL cholesterol were determined by an automated enzymatic techniqueusing a Hitachi 917 autoanalyzer from Roche Diagnostics (Riyadh, Saudi Arabia). LDLcholesterol was calculated using the Friedewald equation: LDL cholesterol $(\mathrm{mmol} / \mathrm{L})=\mathrm{TC}-(\mathrm{TG} / 2.2)-\mathrm{HDL}$ cholesterol, Friedewald equation is inaccurate at higher triglycerides levels, therefore subjects with triglycerides of $\geq 4.52 \mathrm{mmol} / \mathrm{L}$ were excluded from the LDL analysis.Lp(a) was quantified using an immunoturbidimetric assay on the Hitachi 911auto-analyzer. All measured assays were established on Hitachi analyzers 911 or 917 with tested accuracy and precision in addition to the two levels of controls materials (low and high) all ofwhich were meeting the acceptable criteria (data not shown).

\section{lodixanol gradient separation for small dense LDL}

Iodixanol is a contrast media commercially available as Optiprep (Cambridgeshire, UK).Iodixanol is a non-ionic iso-osmotic medium and has been validated for use in this technique dueto its ability to form self-generating gradients. This enables the separation of the LDLsubtractions to form not discrete bands but rather banding patterns, which can then be analyzedusing computer software. As previously described $^{25}$, and in this procedure, the iodixanol gradientwas prepared in a $4.9 \mathrm{~mL}$ tube as follows: first, $1.52 \mathrm{~mL}$ plasma was mixed with Optiprep (60\%(w/v) iodixanol) and prestained with Coomassie blue R-250 (50 mg/mL in PBS; from Sigma,(Milwaukee, WI, USA). In this plasma sample, $0.4 \mathrm{~mL}$ of the Optiprep solution and $80 \mu \mathrm{L}$ of theCoomassie blue solution was added to provide a working sample of $2 \mathrm{~mL}$ with the desired concentrations. The upper layer thus consisted of a $9 \%$ solution of iodixanol prepared usingphosphate buffered saline (PBS) as the diluent, so that the final density is 1.050 $\mathrm{kg} / \mathrm{L}$. Then, $3.4 \mathrm{mLaliquots}$ of this solution were transferred to $4.9 \mathrm{~mL}$ Beckman Optiseal centrifuge tubes. Asyringe and cannula was used to carefully under-layer $1.5 \mathrm{~mL}$ of the working solution. Thetubes were housed in a Beckman NVT65.2 near vertical rotor (Beckman Coulter, Inc. Fullerton,CA, USA). Separation was performed in a Beckman Optima L-100 ultracentrifuge at 370,000 gfor $2.5 \mathrm{~h}$. Post-centrifugation, the tubes were carefully removed from the rotor and photographedwith a Nikon D1X digital camera. Digitalimages were downloaded directly to a PC in whichthey were analyzed using Total-lab 1D gel-scansoftware (Pharmacia UK, Milton Keynes, UK). This software converted the photographs of the stained LDL into LDL profiles comprised of an $\mathrm{x}$-axis of distance $(\mathrm{mm})$ versus a y-axis of pixel intensity. The package then automatically assigned relative electrophoretic migration distance values ( $\mathrm{Rf}$ values) to the principal peak and any other peaks present.

The main drawbacks with this method arethe partialoverlap between LDL and HDL boundariesand the challenge in scaling up for testing larger numbers of patient's samples in hospital or reference laboratories. Furthermore, the minimum sample required for this method is $1.52 \mathrm{~mL}$ plasma compared to $\leq 5 \mu \mathrm{L}$ for some methodsfor measuring/detecting small, dense LDL such as non-denaturing polyacrylamide gradient gel electrophoresis.

\section{Statistical analysis}

The data were analyzed using the following software: (1) JMP from SAS Institute Inc.(Cary, NC, USA); (2) InStatstatistical package from InStatCorporation (InStat, San Diego, USA). The following statistical tests were used: nonparametric analysis of variance(ANOVA), unpaired $t$ test, and the chi-square test. All dataare presented as mean \pm the standard deviation (SD).

\section{Results}

Two hundred and twenty subjects suspected of having CHD underwent coronary angiography and blood draw following a 12-hour fast. Based on coronary angiography data, one hundred and forty subjects were found to be positive for CHD 
Table 1: Summary of subjects' demographic data and test results

\begin{tabular}{lccc}
\hline & CAD $+(\mathrm{n}=140)$ & CAD $-(\mathrm{n}=80)$ & p value \\
\hline Age group(years) $\pm \mathrm{SD}$ & $51 \pm 11.6$ & $41 \pm 10.8$ & $<0.0001$ \\
Male/female & $110 / 19$ & $44 / 35$ & $<0.0001$ \\
Hypertension & 31 & 27 & 0.34 \\
Diabetes (type I + type II) & 63 & 12 & $<0.0001$ \\
Smokers & 49 & 13 & $<0.04$ \\
TC mmol/L \pm SD & $5.0 \pm 1.11$ & $4.75 \pm 1.10$ & 0.099 \\
TG mmol/L \pm SD & $1.93 \pm 0.95$ & $1.45 \pm 0.85$ & $<0.0001$ \\
HDL-C mmol/L \pm SD & $1.09 \pm 0.55$ & $1.33 \pm 0.63$ & 0.0001 \\
TC/HDL-C \pm SD & $5.16 \pm 1.69$ & $4.07 \pm 1.44$ & $<0.0001$ \\
LDL-Cmmol/L \pm SD & $3.06 \pm 01.12$ & $2.79 \pm 1.09$ & 0.08 \\
LPL U/L \pm SD & $35.56 \pm 26.63$ & $27.9 \pm 11.96$ & 0.059 \\
Lp (a) mg/dL \pm SD & $46.87 \pm 45.58$ & $29.06 \pm 17.03$ & 0.019 \\
s,denseLDL g/kg $\pm S D$ & $1.031 \pm 0.0028$ & $1.030 \pm 0.0003$ & 0.0099 \\
$\%$ s,denseLDL:large LDL & $28.55 \pm 13.62$ & $23.38 \pm 90.82$ & 0.01 \\
\hline
\end{tabular}

SD: standard deviation; TC: total cholesterol; TG: triglycerides; HDL-C: high density lipoproteins cholesterol: LDL-C: low density lipoproteins cholesterol: LPL: lipoproteins lipase; Lp(a): lipoprotein(a); s,dense: small dense.

(mean age: 51 years, $79 \%$ men) while 80 subjects were shown to be negative for $\mathrm{CHD}$ (mean age: 41 years, $55 \%$ men). None of subjects had renal disease, previous $\mathrm{CHD}$, myocardial infarction orcerebrovascular disease, and $45 \%$ in the $\mathrm{CHD}$ positive group (mean $\mathrm{HbA} 1 \mathrm{C}=9.0 \%$ ) and $15 \%$ in the CHD negative group (mean $\mathrm{HbA} 1 \mathrm{C}=5.9 \%$ ) haddiabetes mellitus (type I or II). Metabolic syndrome was found in $63 \%$ of the CHD positive compared to only $8 \%$ in the $\mathrm{CHD}$ negative group. Hypertension was found in $22 \%$ of the positive and in $34 \%$ of the CHD negative group. History of Kawasaki disease was reported in one subject in CHD positive group. Table 1shows the main characteristics of the study population including the information's on lipids, lipoproteins and small dense LDL.

Coronary angiography was used to distinguish between normal and diseased coronary arteries, and for determining the severity of disease. A total of 128 subjects (one subject was excluded due to incomplete data) had between one to five diseased vessels, with disease severity ranging from 50 to $100 \%$ occlusion. Of those subjects, $25 \%$ had single vessel disease, $31 \%$ had double vessel disease, $34 \%$ had triple vessel disease, $9 \%$ had four diseased vessels, and $2 \%$ had five diseased vessels. Of these subjects, $85 \%$ had left anterior descending artery (LAD) disease, $64 \%$ had left circumflex (LCX) disease, 12\% had obtuse marginal artery (OMA) disease, 58\% had right coronary artery (RCA) disease, 6\% had left main artery (LM) disease, 6\% had diagonal artery (DI) disease, $4 \%$ had posterior descending artery (PDA) disease, and $1 \%$ had posterior lateral artery (PLA) disease (subjects with multiple vessel disease may overlap in percentage calculations). LAD disease contributed to $84 \%$ of the instances of single vessel disease, $79 \%$ of the instances of double vessel disease, $91 \%$ of the instances of triple vessel disease, and all of the instances of four and five vessel disease.

\section{Discussion}

The Saudi population is renowned for its high incidence of coronary artery disease(CHD) in comparison to other Middle Eastern countries. While the origin of increased CHD riskin this relatively understudied group is unknown this makes the observations in this study somewhat unique.

The hypothesis of this project stated that the predominance of small dense LDL and the elevatedlevels of traditional coronary risk factors influenced by diet and physical inactivity may bemajorrisk factors for the development of CHD in angiographically defined subjects in the Saudipopulation.

The aim of the current research was to undertake a case-controlled study of CHD riskfactors from a randomly selected sample of the Saudi population such as cigarette smoking and hypertension, with a focus on lipidmediatedrisk factors such as TC, TG, Lp(a), lipoprotein lipase, HDL-cholesterol, LDLcholesterol, and small, dense LDL.

In this study, $\mathrm{CHD}+$ group was on average older than the CHD- group, which may addsome influence of the age contribution as a risk to $\mathrm{CHD}$, even after adjustment for age difference this group remained to have higher incidence of $\mathrm{CHD}$ risk factors. The number of females within theCHD+ group were small due to the lesser number of women qualified for the study; in additionthis may provide some evidence that females under the age of 50 years old may be at lower risk of CHD compared to males in the Saudi population similar to what was found in western populations.

Cigarette smoking is known to increase the risk of CHD.Our data showthat smokers were more prevalent in the $\mathrm{CHD}+$ group, these subjects demonstrated multiplesites of atherosclerosis ranging from twoto four vessel disease, except in eightsubjects, in which singlevessel disease was detected. The degree of atherosclerosis was mostly $100 \%$ occlusion withseveral between 50 to $90 \%$. Of these smokers, 37 had slightly increased TG $(>1.5 \mathrm{mmol} / \mathrm{L})$, slightly increased TC (5.2 to $6.99 \mathrm{mmol} / \mathrm{L}$ ) and all had $\mathrm{Lp}$ (a) levels of $>30 \mathrm{mg} / \mathrm{dL}$, whichsuggests that cigarette smoking may play some role as a risk factor by acting synergistically with other risk factors leading to an increasedincidence of CHD in the Saudi population, as has been seen in other populations.

Diabetes iswell-known to have strongrelationshipwith CHD. In this study, diabetes was found to be dominant in CHD positive group.Diabetes may influence the metabolic syndrome, lipid abnormalities and atherosclerosis, all of 
which may lead to CHD as this was previously reported in Western population.

Hypertension was equally distributed in both $\mathrm{CHD}+$ and CHD- groups, but in lesserproportion compared to the nonhypertensive subjects within each group. This finding does not provide strongevidence to support the role of hypertension in the etiology of $\mathrm{CHD}$ in this population, whichdiffers from what was found in other populations. In addition, hypertension may or may notplay a major role in development of CHD in the Saudi population and could possibly besecondarily or non-causally present within the subjects with heart disease.

TC and LDL-cholesterol were not significantly different between the $\mathrm{CHD}+$ and $\mathrm{CHD}$-groups $(\mathrm{p}<0.1)$, suggesting that total and LDL cholesterolmeasurement may have less predictive power on theincidence of CHD in the Saudi population (compared to the other risk factors) which is differentthan what was found in the past in other populations ${ }^{1}$. For both groups mean TC remainedbelow the desired limit $(<200 \mathrm{mg} /$ $\mathrm{dL}$ or $<5.2 \mathrm{mmol} / \mathrm{L}$ ) assigned by the guidelines of the National CholesterolEducation Program (NCEP) Adult Treatment Panel III (ATPIII); the Expert Panel on Detection,Evaluation, and Treatment of High Blood Cholesterol in Adults. This research finding suggeststhat the measurements of TC and LDL-cholesterol are insufficient to discriminate betweenindividuals at risk of $\mathrm{CHD}$ and those who are not at risk. In favor of this finding, some recentresearch has provided more evidence suggesting that smaller LDL particles are more atherogenicand hence more closely associated with $\mathrm{CHD}$, regardless of total or LDL cholesterol levels. Furthermore, TC and LDLcholesterol measurements will not indicate the presence or absence ofsmall, dense LDL and other TG enriched atherogenic particles. Therefore measurement of the latterparameters may add considerable discriminatory power for diagnosing and predictingcardiovascular risk. In conclusion, $\mathrm{CHD}$ is highly related to other risk factors and the TC itselfmay not be a significant predictor of CHD risk in the Saudi population.

As a major component of an atherogenic lipoprotein phenotype (ALP), a predominanceof small, dense LDL has been shown to be present in patients with $\mathrm{CHD}+$ compared to the CHD- group $(\mathrm{p}<0.01)$, with all patients with predominance of thesmall, dense LDL subclass i.e Pattern $\mathrm{B}$ falling into this disease group. This finding mightsuggest that small, dense LDL plays some major role as an atherogenic risk factor for CHD in the Saudipopulation, thus confirming the original hypothesis.

Serumconcentrations of TG were significantly higher in the CHD+ compared to the CHD- group ( $\mathrm{p}<0.0001)$; thus triglycerides were one of the major risk factors for CHD in the Saudi population. This relationship may have amultifactorial origin and could arise from metabolic defects associated with obesity, as found inmetabolic syndrome and diabetes, or in response to a high fat and/or carbohydrate diet or tophysical inactivity, all of which may contribute to the production of small, dense LDLandincrease risk of CHD in the Saudi Arabian population. These current findings would supportrecommendations to modify lifestyle through diet changesin addition to exercise as a first line of prevention againstCHD. This may require medication to lower serum TG, all of which may improvehealth and reduce the incidence of $\mathrm{CHD}$ in this population.

RCT is known to be a function of HDL. In this study, serum HDL was found to be significantly lower in the CHD+ group compared tothe CHD- group ( $\mathrm{p}=0.0001$ ), which may indicate either decreased synthesis or increasedcatabolism of HDL, and that as a result, cholesterol efflux may be compromisedin this population. The transforming of HDL into smaller and denser particles by increased serumTG may underlie the rapid clearance of HDL from the circulation, thus increasingthe demand on HDL in RCT.

The TC/HDL-cholesterol was significantly higher in the $\mathrm{CHD}+$ group compared to the $\mathrm{CHD}$ - group $(\mathrm{p}<0.0001)$. This is due to significantly lower HDL-cholesterol in the CHD+ group, theHDL-cholesterol concentration alone was very nearly as statistically significant $(\mathrm{p}=0.0001)$ asthe TC/HDL ratio, and not due to elevated TC. In thisstudy, TC/HDL ratio of $>4.1$ may discriminate between individuals at $\mathrm{CHD}$ risk from those whoare not at risk in Saudi population.

The activity of total LPL in post-heparin plasma was found to be higher in the $\mathrm{CHD}+$ groupcompared to the CHD- group, but not significantly so $(\mathrm{p}<0.059)$. LPL is known to be the keyenzyme in hydrolyzing the triglycerides carried by lipoproteins to provide the tissue withfatty acids $^{26}$. Low levels of plasma LPL have been associated with increased TG levels whichmay promote and increase incidence of $\mathrm{CHD}^{27,28}$. The result of this research finding differs fromthat previously reported in regards to the low level of LPL activity and its relation to CHD.

Lp (a) was significantly higher in the CHD+ group compared to the CHD- control group $(\mathrm{p}=0.019)$ as previous studies had shown that high plasma $\operatorname{Lp}(\mathrm{a})$ is associated with prematurecoronary atherosclerosis ${ }^{29}$. The findings from the present study suggest that $\mathrm{Lp}(\mathrm{a})$ may play a role in identifying andpredicting individuals at risk for CHD in the Saudi population.

In conclusion, the findings of this study would sggest that the assessment of CHD risk by measurement of a traditional serum lipid profile (TC, LDL-cholesterol, HDLcholesterol, TG)may be inadequate in this particular population. The addition of small, dense LDL measurement, 
may further improve the ability to discriminate individuals at CHD risk in the Saudipopulation.

\section{Acknowledgment}

We would like to thanks G Russell Warnick (Health Diagnostics Laboratory, Richmond, VA) for his help onreview and editing this paper.

Many thanks for Bruce Griffin for his help providing the laboratory and support for measuring small dense LDL at Nutritional Sciences, University of Surrey, Guildford, Surrey GU2 7TE, UK.

\section{References}

1. Dawber TR, Meadors GF, Moore FEJ. Epidemiological approaches to heart disease: theFramingham Study. Am J Public Health. 1951;:41:279-86

2. Anderson KM, Castelli WP, Levy DL. Cholesterol and mortality: 30 years follow up from theFramingham study. JAMA. 1987;257:2176-80.

3. Assmann G, Schulte H, Cullen P. New and classical risk factors--the Münster heart study(PROCAM). Eur J Med Res. 1997;2(6):237-42.

4. Mänttäri M,Elo o, Frick MH, et al. The Helsinki Heart Study: basic design and randomizationprocedure. Eur Heart J. 1987;8Suppl I:1-29.

5. Frick MH, OElo O, Haapa K, et al. Helsinki Heart Study: primaryprevention trial withgemfibrozil in middle-aged men with dyslipidemia. Safety of treatment, changes in risk factors,and incidence of coronary heart disease. N Engl J Med. 1987;317(20):1237-45.

6. Hokanson J, Austin M. Plasma triglyceride and coronary risk. A meta-analysis. Circulation. 1993;88:523-33.

7. Miller M. Is hypertriglyceridaemia an independent risk factor for coronary heart disease?Eur Heart J. 1998;19Suppl H:H18-22..

8. Iso H, Naito Y, Sato S, et al. Serum Triglycerides and Risk of Coronary Heart Disease among Japanese Men and Women.Am J Epidemiol. 2001;153:490-9.

9. Hokanson JE, Austin MA. Plasma triglyceride level is a risk factor for cardiovasculardisease independent of high-density lipoprotein cholesterol level: a meta-analysis of population19based prospective studies. J Cardiovasc Risk. 1996;3(2):213-9.

10. Ohashi R, Mu H, Wang X, et al. Reverse cholesterol transport and cholesterol efflux in atherosclerosis. QJM. 2005;98:845-56.

11. Tall AR, Costet P, Wang N. Regulation and mechanisms of macrophage cholesterol efflux. J Clin Invest.2002;110:899-904.

12. Austin MA, Breslow JL, Hennekens $\mathrm{CH}$, et al. Low-density lipoprotein subclass patterns and risk of myocardial infarction. JAMA. 1988;260:1917-21.

13. Griffin BA, Freeman DJ, Tait GW, et al. Role of plasma triglyceride in the regulation of plasma low density lipoprotein (LDL) subfractions: relative contribution of small, dense LDL to coronary heart disease risk. Atherosclerosis. 1994;106:241-53.

14. Gardner CD, Fortmann SP, Krauss RM. Association of small lowdensity lipoprotein particles with the incidence of coronary artery disease in men and women. JAMA. 1996;276:875-81.
15. Stampfer MJ, Krauss RM, Ma J, et al. A prospective study of triglyceride level, low-density lipoprotein particle diameter, and risk of myocardial infarction. JAMA.1996;18;276(11):882-8.

16. Krauss RM. The tangled web of coronary risk factors. Am J Med. 1991;90:36S-41S

17. Krauss RM. Dense low density lipoproteins and coronary artery disease. Am J Cardiol. 1995;75(6):53B-57B.

18. Krauss RM. Is the size of low-density lipoprotein particles related to the risk of coronary heart disease? JAMA. 2002;287:712-3.

19. Williams PT, Superko HR, Haskell WL, et al. Smallest LDL particles are most strongly related to coronary disease progression in men. ArteriosclerThrombVasc Biol. 2003;23:314-21.

20. Grundy SM. Hypertriglyceridemia, insulin resistance, and the metabolic syndrome. Am J Cardiol. 1999 May;83(9B):25F-29F.

21. Haffner SM. Epidemiology of insulin resistance and its relation to coronary artery disease. Am J Cardiol. 1999;84(1A):11J-14).

22. Bernies KK, Krauss RM. 2002. Metabolic origins and clinical significance of LDL heterogeneity. J Lipid Res. 2002;43:1363-79.

23. La Belle M, Krauss RM. Differences in carbohydrate content of low density lipoproteins associated with low density lipoprotein subclass patterns. J Lipid Res. 1990;31:1577-88.

24. Al-Hazzaa HM. Physical activity, fitness and fatness among Saudi children and adolescents: implications for cardiovascular health. Saudi Med J. 2002;23(2):144-5.

25. Davies IG, Graham JM, Griffin BA. Rapid Separation of LDL Subclasses bylodixanol Gradient Ultracentrifugation. Clin Chem. 2003;49:1865-72.

26. Fielding BA,Frayn KN. Lipoprotein lipase and the disposition of fatty acids. Br J Nutr. 1998;80:495-502.

27. Jukema JW, van Boven AJ, Groenemeijer B, et al. The Asp9Asn mutation in the lipoprotein lipase gene is associated with increased progression of coronaryatherosclerosis. Circulation. 1996;94:1913-8.

28. Kastelein JJP, Jukema JW, Zwinderman AH, et al. Lipoprotein lipase activity isassociated with the severity of angina pectoris. Circulation. 2000;102:1629-33.

29. Guazzeli R, Fatini C, Piazzini M, et al. Lipoprotein(a): genetic marker of precociousmyocardial infarction. Ann ital Med Int. 1996;11:90-4.

Correspondence: MohmedElfatihAshmaig Berkeley Heart Lab. Inc 960 Atlantic AVE,

Alameda, CA 94501, USA E-mail:moh20_2000@yahoo.com

Author contributions Conception and design: MEA, KA, AA, SS, MA Analysis and interpretation: MEA Data collection: MEA, KA, AA, SS, MA Writing the article: MEA Critical revision of the article: MA, KA, SS, MA Final approval of the article*: All Statistical analysis: MEA

Overall responsibility: MEA Obtained funding: N/A * All authors should have read and approved of the final version of the article submitted to J Vasc Bras. 